\title{
Sistemas de la violencia sociopolítica
}

\author{
Cruz García Lirios \\ Javier Carreón Guillén \\ Jorge Hernández Valdés \\ Agustín Méndez Martínez
}

Universidad Nacional Autónoma de México (ENTS), Ciudad de México, México.

Email: garcialirios@gmail.com

\begin{abstract}
Resumen: La seguridad nacional está asociada con un grado de violencia tal que incluso los medios de comunicación la deben minimizar o maximizar, según sus intereses, para incidir en la opinión pública y la agenda política. La Teoría del Establecimiento de la Agenda (TEA) ha explicado el sesgo de los medios con respecto a los hechos y las políticas de seguridad nacional del Estado. En virtud de que los homicidios son el indicador principal de violencia en México, el presente trabajo se avocó a discutir la relación asimétrica entre Estado, medios de comunicación y ciudadanía. Para tal propósito, se revisan las formas y los regímenes de gobierno como la causa del grado de violencia en el país. Posteriormente, se explica la relevancia de la violencia en referencia a los medios de comunicación y su función mediática de los hechos. La discusión del poder sociopolítico coercitivo y persuasivo facilitó una propuesta metodológica en dos etapas circunscritas a la TEA.
\end{abstract}

Palabras clave: Sistema, Violencia, Estado, Medios y Agenda.

\section{Systems of sociopolitical violence}

\begin{abstract}
National security is associated with a degree of violence such that even the media should minimize or maximize, according to their interests, to influence public opinion and the political agenda. The Theory of the Establishment of the Agend (TEA) has explained the bias of the media regarding facts and national security policies of the state. Under that homicides are the leading indicator of violence in Mexico, this work focused on discussing the asymmetrical relationship between State, media and citizenship. For this purpose, we review the forms and systems of government as the cause of the level of violence in the country. Subsequently, we explain the relevance of the reference to violence in media and media function of the facts. The discussion of the coercive and persuasive sociopolitical power provided a methodology in two stages confined to the TEA.
\end{abstract}

Key words: System, Violence, State, Media and Setting.

\section{Sistemas de violência sociopolítica}

Resumo: A segurança nacional está associado a um grau de violência de tal forma que até mesmo os meios de comunicação devem minimizar ou maximizar, com base em seus interesses, para influenciar a opinião pública e da agenda política. Agenda Setting Theory (TEA) explicou a parcialidade da imprensa com relação 
aos fatos e as políticas de segurança nacional do Estado. Tendo em conta que o homicídio é o principal indicador de violência no México, este trabalho se concentrou em discutir a relação assimétrica entre o Estado, os meios de comunicação e cidadania. Para isso, os métodos e sistemas de governo como a causa do grau de violência no país são revistos. Posteriormente explicou, a pertinência da referência à violência nos meios de comunicação e mídia, dependendo dos fatos. A discussão do poder sociopolítico coercitivo e persuasivo forneceu uma proposta metodológica em duas etapas confinados ao TEA.

Palavras-chave: Sistema, Violência, Estado, Mídia e Eventos.

$* * *$

\section{Introducción}

En México la violencia sociopolítica definida como el sesgo informativo en torno a la prevalencia de un delito respecto a otros delitos, en un espacio determinado por la agenda de los medios de comunicación, y en referencia a la opinión pública de las políticas públicas del Estado para combatir dicha prevalencia mediática, alude a un contexto en el que la inseguridad pública es reducida a una prevalencia de homicidios en la frontera norte a pesar de que el centro del país tiene un mayor número de casos.

La violencia sociopolítica implica a tres actores: Estado, medios de comunicación y ciudadanía inmersos en la perspectiva de un país inseguro y violento en el que la acción gubernamental ha sido evaluada por la opinión pública como corrupta, pero matizada como mal necesario para seguridad nacional por los medios de comunicación cercanos a la política de seguridad y como acción innecesaria por los medios de comunicación críticos.

Ante este panorama el análisis de la violencia sociopolítica podría llevarse a cabo a partir de los sistemas políticos coercitivos y persuasivos así como desde la Teoría del Establecimiento de la Agenda (TEA). Dos hipótesis sustentarían el análisis: el sesgo informativo coercitivo y la manipulación comunicativa persuasiva.

La primera sostiene que los medios de comunicación seleccionan los contenidos de sus programas a partir de criterios coercitivos más que de veracidad o verosimilitud de los hechos. Se trata de un sesgo mediático puesto que los hechos, una vez que han ocurrido son susceptibles de ser reducidos o amplificados por parte de reporteros, comentaristas o comunicadores. En el caso de la violencia, la interpretación que los medios llevan a cabo de los hechos es transmutado en noticias, reportajes o comentarios. Tal metamorfosis reduce el contenido de un hecho a un lenguaje accesible para las audiencias. Sin importar la magnitud de los eventos, los medios de comunicación y el Estado contextualizan, enmarcan e intensifican las relaciones entre los hechos. 
La segunda hipótesis plantea que el sesgo de los hechos por parte de los medios de comunicación y el Estado lleva a las audiencias a procesar las imágenes y los datos de modos distintos. Las audiencias que perciben los hechos a partir de imágenes con un bajo discurso interiorizan los mensajes para desarrollar sentimientos o afectos respecto a los eventos. Las audiencias que procesan datos, tienden a cuestionar los mensajes estadísticos o gráficos y desarrollan necesidades de cognición que las llevarán a buscar más información al respeto, contrastar las versiones de los medios y construir argumentos a favor o en contra de los sesgos mediáticos.

Ambos procesos, afectivo y racional en torno a los mensajes con respecto a los hechos, se construyen en escenarios sociopolíticos en los que el poder de persuasión y disuasión están presentes. Es decir, la relación entre los medios de comunicación y las audiencias está permeada de asimetrías en las que los individuos pueden ser persuadidos o disuadidos en sus opiniones. En el caso de la violencia, las imágenes pueden influir en quienes opinan que el país se encuentra bajo un clima de concordia. O bien, los datos estadísticos pueden disuadir a quienes piensan que la violencia es un mal endémico.

Precisamente, el objetivo del presente trabajo es discutir los alcances y los límites de la TEA en referencia a los casos de homicidios reportados en el año 2010 por el Instituto Ciudadano de Estudios sobre la Inseguridad A. C. El análisis permitirá construir una metodología para el estudio de la violencia a partir de las dos hipótesis de la TEA expuestas líneas arriba. El ejercicio reflexivo y metodológico permitiría esclarecer el impacto de la cobertura de los medios de comunicación sobre la percepción de inseguridad pública y las políticas públicas del Estado ante la coyuntura de violencia sociopolítica indicada por la prevalencia de homicidios. Por último, el análisis permitirá develar dos sistemas políticos: uno coercitivo y otro persuasivo inherentes a la violencia sociopolítica.

\section{Sistemas sociopolíticos coercitivos y persuasivos}

\section{Un sistema, definido como un modelo de factores orgánicos abier-} tos al intercambio de energía con otros sistemas, fue planteado por Bertalanffy (1968) para explicar la estructura de la biosfera. Esta propuesta fue retomada por Luhmann (1986) para referir a la autoorganización comunicativa del poder. A diferencia de Bertalanffy, quien afirma que todo sistema esta organizado a partir del intercambio con su entorno, Luhmann (1992) sostiene que el Estado es un sistema de comunicación que se especializa en la persuasión de sus subsistemas. La simplicidad política es una dimensión coercitiva del Estado derivada de la ilegitimidad electiva y concentración del poder en un líder o grupo. La simplicidad coercitiva alude a procesos irracionales en los que la personalidad del líder o la dinámica del grupo en el poder determinan sus decisiones y acciones sin considerar los costos y los beneficios de sus convicciones. La simplicidad ilegitima se sustenta en una ética carente de responsabilidad y propensión al futuro. Se 
trata de una aversión a la certidumbre en la que las emociones definen el rumbo de un Estado. El azar aunado a la mística parecen ser considerados para emprender conflictos en nombre del nacionalismo, la identidad, el poder e ideología. La simplicidad coercitiva representa una dimensión de la historia de la humanidad en la que los conflictos producían cambios aún a pesar de que tales discrepancias se sustentaran en los límites personales o grupales que ilegítimamente representan a un Estado. La simplicidad política es un mecanismo de coerción de los sistemas tribales, autoritarios, totalitarios o en transición que aspiran a la democracia, aunque ésta implique un cambio diversificado en las formas de Estado y los regímenes de gobierno (ver figura 1$)$.

\section{Figura 1. Los sistemas políticos}

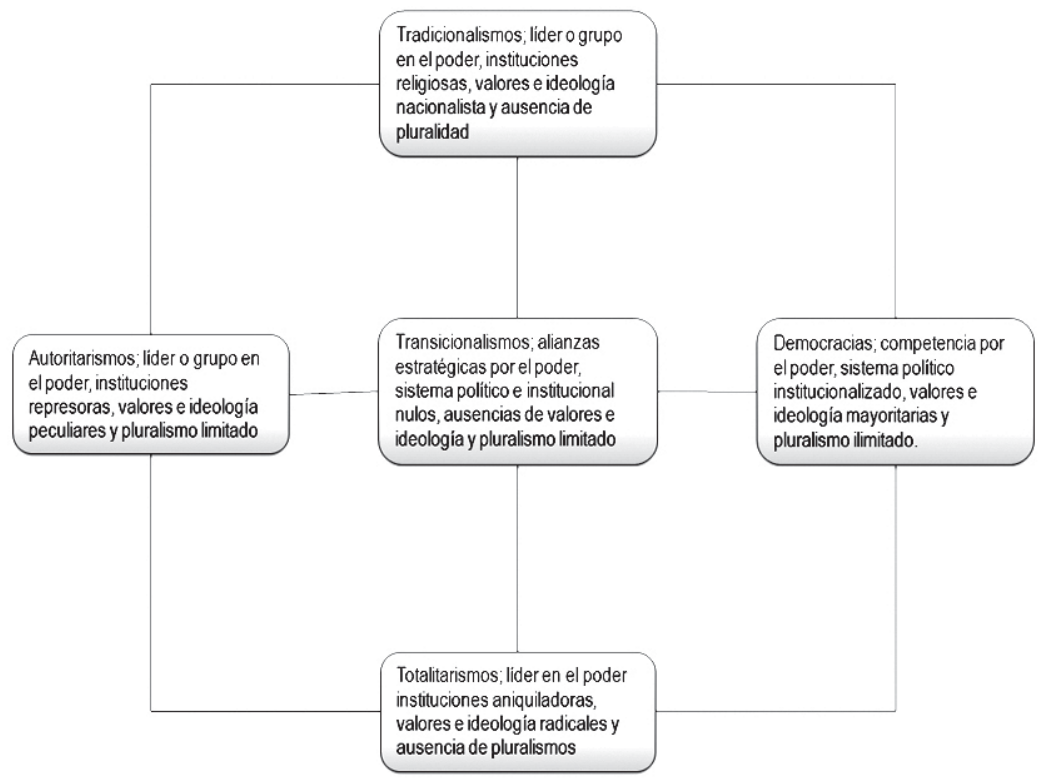

El pensamiento sistémico luhmaniano parece coincidir con la propuesta de un Estado moderno sólido. Bauman (1998) sostiene que las ciudades fueron construidas bajo el principio de modernidad que consiste en seguridad e identidad en torno a un Estado omnipresente. Las urbes fueron edificadas para proteger a sus habitantes de las invasiones o inundaciones. Toda ciudad moderna, tenía un centro de poder en el que ubicaban panópticos que permitían la vigilancia interna y externa. Durante esta etapa de modernidad, el Estado era sinónimo de solidez y robustez. Este planteamiento baumaniano del poder monopólico del Estado, concuerda con el concepto luhmaniano de autorganización sistémica. El Estado, es un sistema que se 
organiza en torno a sus elementos internos y factores externos que justifiquen su coerción. Ambos, son esenciales para el funcionamiento sistémico del Estado. Los elementos endógenos, al ser amenazados por los factores externos, necesitan someterse a un sistema de coerción que garantice su seguridad. Tanto Bauman como Luhmann piensan en un Estado coercitivo que unifica las simetrías y extermina las asimetrías.

Sin embargo, entre el planteamiento baumaniano y la propuesta luhmaniana hay una diferencia sustancial que alude a la modernidad del Estado. Para Bauman (2002) el mercado esta sustituyendo al Estado, para Luhmann el Estado se ha complejizado hasta un punto tal que el mercado es un nuevo mecanismo de control persuasivo.

El Estado guiddeniano refiere a una autoestructuración de sus subsistemas endógenos. Se trata de una democracia estructurante. Es decir, los elementos endógenos del Estado convergen en normas que los diferencian de los factores exógenos. Más aún, los elementos internos del régimen, son considerados, en primera instancia, súbditos por Guiddens (1979) porque sólo internalizan sus normas coercitivas. Luhmann sostendría que el Estado, en tanto se organiza internamente, determina sus subsistemas endógenos, pero son éstos elementos internos los que configuran al régimen. Si la política es el debate de ideas y la construcción de consensos en torno a una agenda, entonces el Estado incide en el debate público a través de sus instituciones de gobierno al mismo tiempo que los individuos, grupos, asociaciones, sindicatos, gremios, agrupaciones, conglomerados y sociedades reconfiguran su gobernanza. En este nivel de análisis, Luhmann parece referir a una democracia participativa en el mismo sentido planteado por Kymlicka (1969). El filósofo alemán parece convenir con el filósofo canadiense en la idea de participación política como complemento de la estructuración del Estado. Es aquí donde el mercado tiene cabida en el esquema sistémico del poder político, las formas de gobierno y los regímenes de Estado.

El mercado, aparece como un tercer poder, incluso coercitivo, entre el Estado y sus elementos endógenos que Kymlicka (1995) llama ciudadanía participativa y Guiddens reconoce, en segunda instancia, como agencia. Estado, mercado y ciudadanía serían estructuras de un mismo sistema develado por su tendencia a excluir la diversidad que atente contra su estructuración política coercitiva. Esta triada en tanto sistemas interdependientes o subsistemas convergentes de coerción son los fundamentos sistémicos de la realidad política. Es decir, los individuos que integran las instituciones, las personas que trabajan en las organizaciones y los ciudadanos que participan en las sociedades, son factores de coerción con el objetivo de excluir a portadores de normas, valores y creencias que diversifiquen la realidad política.

La coerción política esgrime instituciones pretorianas que se encargaban de ejecutar los designios de los líderes. Tales instituciones mantenían una vigilancia sobre los súbditos porque eran considerados disidentes 
y por ello había que someterlos a un régimen represivo que les impidiera vaticinar cambios estructurales desfavorables al sistema (ver figura 2).

\section{Figura 2. Los sistemas políticos coercitivos}

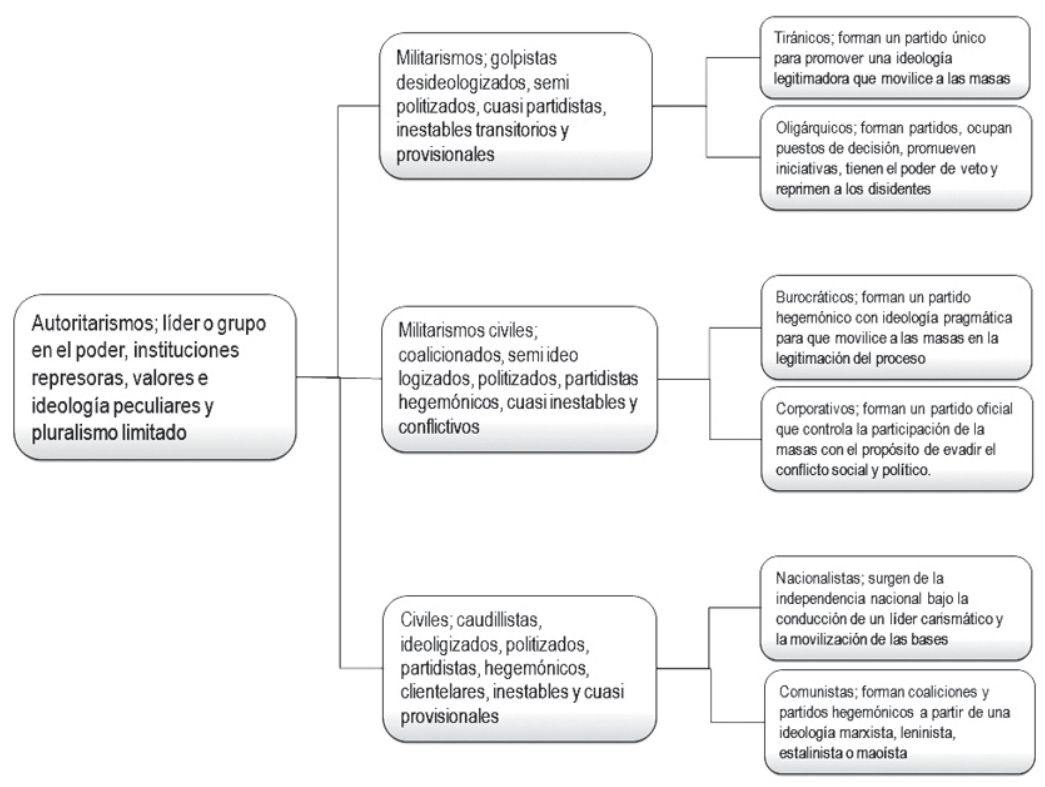

No obstante, los avances técnicos y científicos incrementaron el intercambio comercial entre los feudos y con ello el aumento de la población fue considerada una amenaza para el régimen. Por ello, las fronteras se abrieron al comercio y la migración. Ambas germinaron en ideas de libertad. Una vez puesta en marcha la ideología liberal se requería de instituciones que contribuyeran a la legitimidad de la república reduciendo la disidencia a un plano crítico disuasivo de las movilizaciones armadas.

Una vez creadas las constituciones, los partidos, los líderes, los simpatizantes e incluso los disidentes, se firmaron los protocolos para legitimar la contienda, el debate, los comicios, la transferencia y el ejercicio del poder político. El nuevo sistema se diversificó, fue adoptado y ajustado según las características de la ciudadanía y sus integrantes.

En sociedades individualistas tales como las europeas y las norteamericanas, en el ámbito público, los Estados otorgan autonomía absoluta o relativa a sus ciudadanos para que en el ámbito privado su autocontrol determine decisiones y acciones personales más que grupales, sectoriales o 
sociales. El crecimiento y la prosperidad económica es el resultado de esfuerzos, capacidades, conocimientos, habilidades e innovaciones individuales.

En sociedades colectivistas tales como las latinas o asiáticas, los Estados intervienen en las esferas públicas y privadas para contribuir a la identidad y el arraigo de sus ciudadanos. El Estado apela al crecimiento, al avance y al progreso como resultado de la unión de las diferencias y las desigualdades, la solidaridad y la cooperación.

En el plano político, el sistema persuasivo no ha sido diversificado del todo a pesar de que cuenta con tres modelos de representación y gobernanza. Se trata del parlamentarismo, el presidencialismo y el semipresidencialismo. El sistema presidencialista ha sido asociado con la concentración del poder de iniciativa y el poder de veto, y estaría relacionado con los sistemas coercitivos puesto que en sociedades con un presidente tienden al populismo. Es decir, el poder de iniciativas y el poder de veto no han sido desarrollados como instrumentos persuasivos, sólo como instrumentos de desequilibrio en torno a la relación entre el ejecutivo, legislativo y judicial. La prevalencia del ejecutivo sobre las otras figuras políticas abre la posibilidad de un sistema clientelar ya que las decisiones populistas estarían en función del electorado. El desarrollo de un sistema político persuasivo implicaría el sesgo deliberado los problemas económicos y políticos en función de la racionalización de la opinión pública y un proyecto colectivo de nación (ver figura 3).

\section{Figura 3. Los sistemas políticos persuasivos}

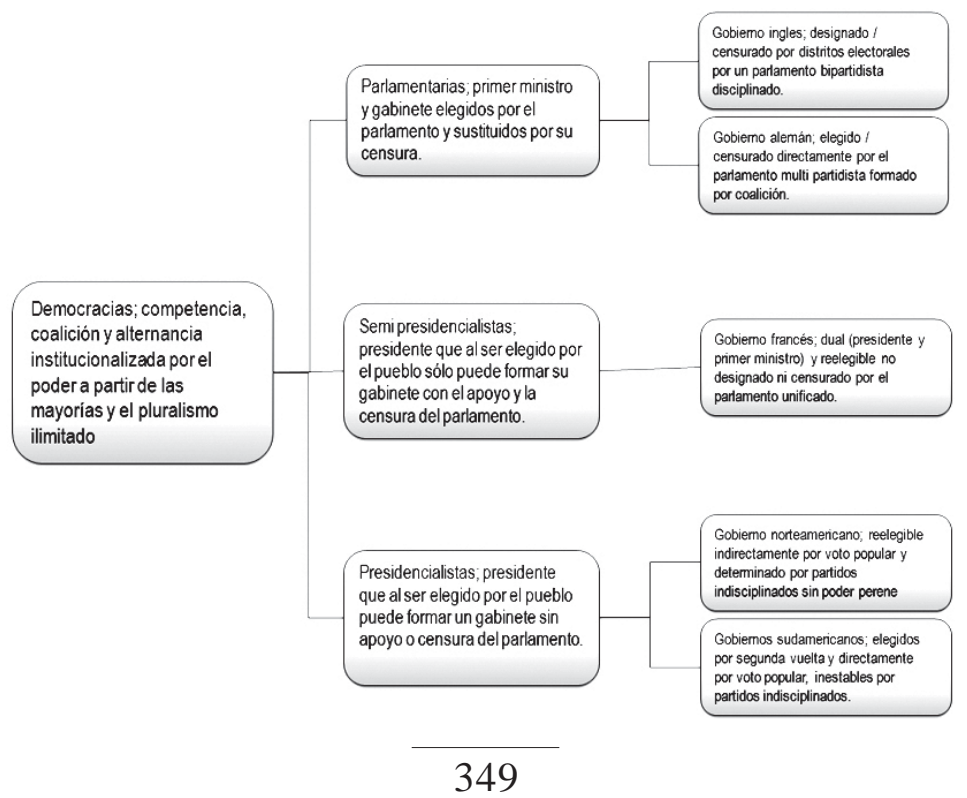


Sin embargo, los sistemas persuasivos en el futuro parecen orientarse hacia dos formas de Estado y regímenes de gobierno. Dado que el deterioro ecológico amenaza cada vez más a economías, regímenes políticos y ciudadanos-consumidores, el nuevo modelo de desarrollo sustentable definirá dos sistemas complejos: aversión ó propensión al futuro. El primero se caracterizará por un amplio espectro de opciones partidistas, candidaturas, debates, contiendas en general que vaticinaran a la escasez o extinción de recursos y distribución condicionada entre las especies animales y vegetales, las generaciones actuales y futuras como su principal justificación, estrategia, plataforma y legitimidad política. El segundo tendrá una amplia gama de ideas en las que cada una serán discutidas para definir una agenda universal como principal estandarte de disponibilidad y distribución equitativa de los recursos entre especies y generaciones (ver figura 4).

\section{Figura 4. Los sistemas persuasivos futuros}

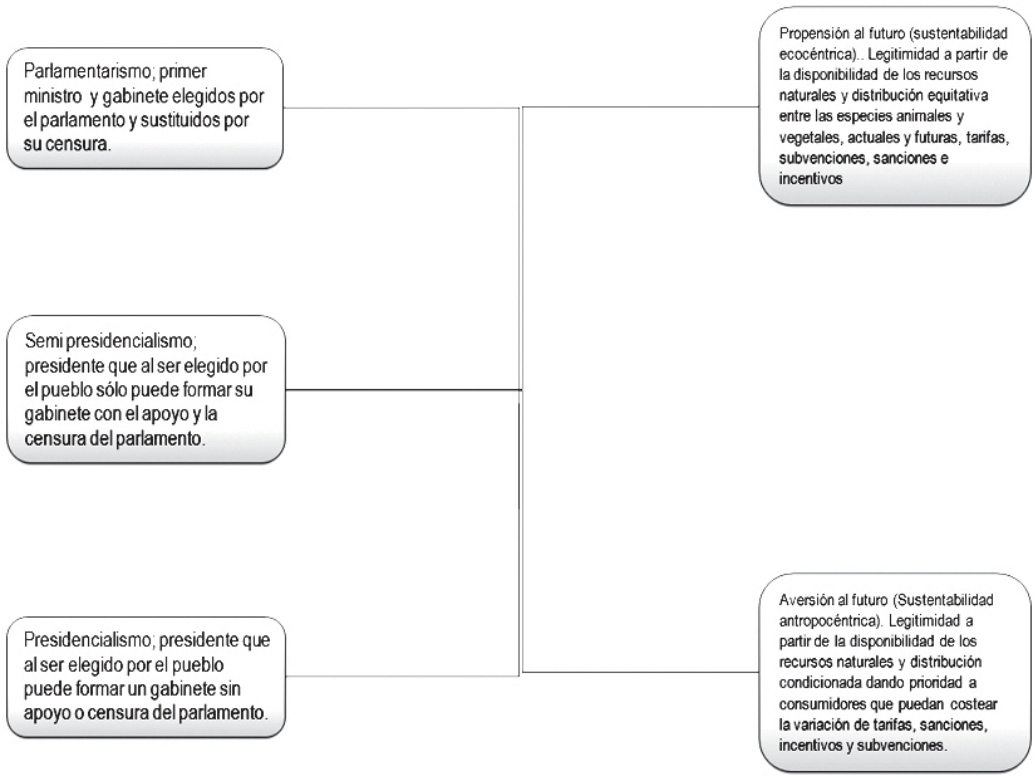

En síntesis, la simplicidad coercitiva y la complejidad persuasiva son políticas de aversión y propensión al futuro construidas por instituciones tanto ilegítimas como legítimas en torno a las cuales coexisten desigualdad e igualdad, represión y libertad, injusticia y justicia, sometimiento y dignidad, irracional y racionalidad, disidentes y adherentes, estructura y coyuntura, economía y comunidad, globalización e identidad. En suma, Estado y ciudadanía. Tal coexistencia se debe a la transferencia sesgada y manipulada de información por parte 
de los medios de comunicación masiva de una entidad política a una entidad cívica.

El Estado, en su proceso evolutivo que va de la simplicidad coercitiva a la complejidad persuasiva, ejerce su poder sobre la ciudadanía predominantemente en imágenes y discursos que por un lado propician emociones y comportamientos intermitentes y por el otro provocan razonamientos sistemáticos sobre su legitimidad (ver figura 5).

\section{Figura 5. La mediatización sistémica de la política}

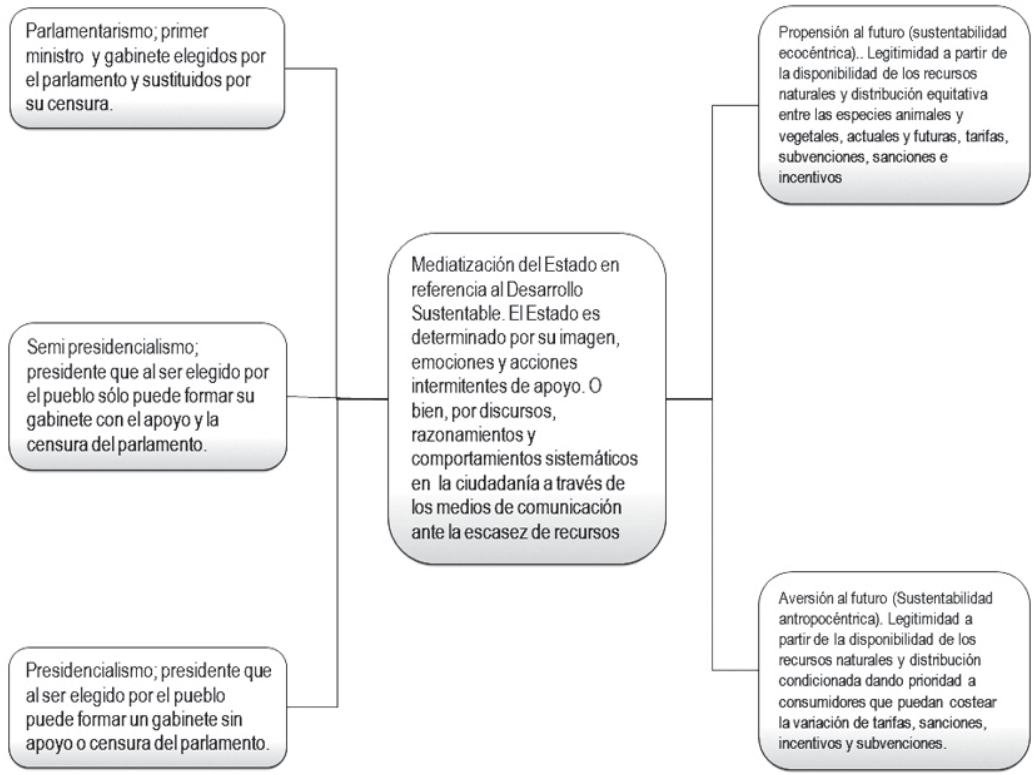

El Estado puede ser coercitivo, estructurante al individuo mediante sus instituciones según Giddens (1979), pero es en esencia un modelo persuasivo que excluye del poder a sus subsistemas competidores para autoorganizarse. Bauman (2005) se aproxima al concepto luhmaniano de Estado al considerar que evolucionó para ser considerado un instrumento de seguridad, confort e identidad para los habitantes de la zona central sólida urbana en referencia a la inseguridad, pauperización y desarraigo de los migrantes asentados en la periferia urbana. Sin embargo, Luhmann aclara que en tanto sistema, el Estado diversifica las relaciones de poder que tiene con sus subsistemas. Si el Estado Baumaniano ha transitado de la solidez a la liquidez, el Estado luhmaniano ha transitado de la simplicidad a la complejidad, de la coerción a la persuasión. 
En esencia, el Estado Moderno y su sistema político persuasivo difunden imágenes más que discursos porque tales símbolos propician indecisión e inacción entre los habitantes de un territorio.

Luhmann sostiene que un sistema autoevoluciona a partir de un subsistema persuasivo regulador de las desigualdades entre sus elementos endógenos. En esencia, éste subsistema ha evolucionado de otro que empleaba la coerción para dividir y unir a los subsistemas. Este sistema regulador es persuasivo porque controla los flujos de información que les permitirían a las personas tomar decisiones acordes a la situación por la que atraviesa el sistema. En la concepción luhmaniana, el control de los medios masivos de comunicación provee de un poder limitado al Estado ya que las nuevas tecnologías y sobre todo su evolución, conllevan más costos que beneficios. El Estado debe evitar envolverse en la incertidumbre que caracteriza a las sociedades. Incluso, mediante campañas políticas, el Estado debe disuadir a los factores exógenos que lo amenazan y persuadir a los elementos endógenos que lo fortalecen. El Estado totalitario o autoritario que controló los medios de comunicación terminó por construir una imagen de injusticia. En cambio, el Estado que otorga libertades a los medios se somete a la crítica, infundada, de sus disidentes e incluso simpatizantes. Por ello, el Estado debe mostrarse con apertura al dialogo, al debate, al plebiscito, al juicio moral, social y político. El Estado alcanza su legitimidad construyendo una imagen que el electorado perciba como justa o cuando menos, no injusta. Luhmann descubrió primero que nadie, el futuro mediático del Estado y enfocó su análisis en la comunicación con sus subsistemas. En tiempos donde la imagen se impone al discurso, el Estado requiere de publicistas, mercadólogos y diseñadores más que de estrategas antimotines, policías antidisturbios o periodistas proselitistas. En efecto, la justicia es un tema que se olvida en la medida en que la apariencia de la imagen se impone como instrumento de legitimidad y legalidad ante la percepción del electorado. En este sentido, Kymlicka (1995) advierte que la participación ciudadana debe ir más allá de la exigencia, la crítica o la manifestación, la libertad le ha sido otorgada al individuo para construir un sistema redistributivo del poder en el que los contrapesos son fundamentales para su conservación. No obstante, Bauman (2008) asegura que al vivir en un sistema consumista no será necesaria la perpetuación del Estado, la persuasión subsistémica o la participación multicultural porque antes de que eso ocurra el sistema se habrá autoliquidado. Es decir, los medios de comunicación en tanto subsistema persuasivo de la complejidad política, seleccionan y difunden los temas que la opinión pública, en primera instancia, y el Estado, en última instancia, adoptaran en una agenda pública de discusión.

McCombs (1972) elaboró la Teoría del Establecimiento de la Agenda para explicar dos mecanismos subsistémicos de selección y difusión de los temas que la opinión pública y la clase política adoptará como agenda de discusión pública. Los titulares y encabezados de los medios de comunicación masivos son elaborados a partir de criterios mediáticos tales como los niveles de audición y comercialización. En este sentido, los eventos, 
sucesos o hechos no implican necesariamente la cobertura mediática sino implican altos niveles de expectación e interés de patrocinadores. Debido a que la cobertura mediática es diferente a los hechos porque los maximiza, los minimiza, los omite o los distorsiona, los medios de comunicación inciden directamente en la agenda pública e indirectamente en la agenda política. McCombs considera a la televisión, la radio y los periódicos no como medios transmisores de los acontecimientos públicos sino como productores de información. En este sentido, los públicos no son los receptores de la información sino intermediarios que transmiten los intereses informativos de los medios para incidir en las políticas públicas. McCombs concibe a los medios de comunicación como estructuras persuasivas que determinan tanto los elementos endógenos como los elementos exógenos del sistema político. Al seleccionar y difundir determinados hechos, los medios de comunicación definen la inclusión y exclusión de temas y criterios de discusión correspondientes. Al incidir en la opinión pública, los medios de comunicación homogenizan los subsistemas persuasivos reduciendo las libertades a una agenda mediática.

En tal sentido, McCombs contrapone el termino audiencia al concepto de participación de Kymlicka. La justicia es para McCombs el resultado de una selección y difusión de temas y criterios para su discusión. La agenda mediática para Kymlicka es el resultado de la participación racional ciudadana. La audiencia en el planteamiento mccombsiano es intermediaria y transmisora de la información fragmentada y reducida a imágenes que influirán en las protestas, mítines, marchas, bloqueos y manifestaciones colectivas que en la concepción kimlickaniana son el resultado de la racionalidad individual y la discusión pública.

La Teoría del Establecimiento de la Agenda de McCombs complementa el planteamiento baumaniano de la modernidad líquida. Si la modernidad sólida se sustentaba con los subsistemas coercitivos tales como el ejército que proveía seguridad a los súbditos, la posmodernidad líquida se construye con subsistemas persuasivos tales como los medios de comunicación que proveen criterios de discusión de temas a los públicos o audiencias. No obstante, McCombs estaría en desacuerdo con Bauman sobre la liquidez del sistema político. El Estado, su sistema persuasivo y sus subsistemas mediáticos, son productores de información que las audiencias adoptan en forma de valores, normas, percepciones, creencias, actitudes, motivos e intenciones improvisadas, pero permanentes porque se activan cada vez que las audiencias discuten un tema. Es decir, el sistema de la complejidad política se perpetúa a través de la estructura de creencias y valores provocados por la selección y difusión de información. En este punto, McCombs (1972) y Giddens (1991) interceptan sus teorías al evidenciar la primacía de las normas, valores y creencias sobre los conocimientos de la opinión pública y las políticas públicas.

La relación asimétrica en el Estado y la ciudadanía, al estar mediatizada, produce afectividad discursiva más que conflicto y cambio. Es decir, los símbolos en torno a la disponibilidad y distribución de los 
recursos naturales a partir de derechos, capacidades, necesidades y expectativas de la ciudadanía delinean creencias, decisiones y acciones antropocéntricas que por su naturaleza emotiva son intermitentes (ver figura 6).

\section{Figura 6. Afectividad de la complejidad política}

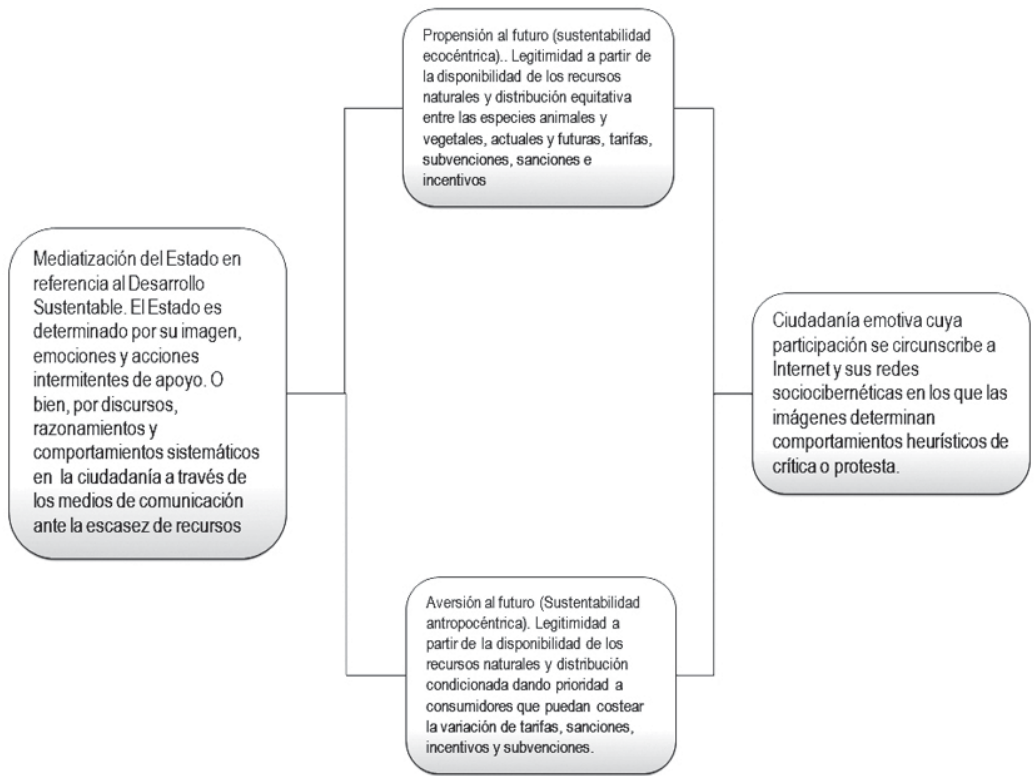

Si la complejidad de un sistema consiste en un incremento de la identidad ciudadana hacia su Estado, si la identidad denota acuerdos y desacuerdos con el Estado, si los subsistemas muestran la diversificación del poder, entonces el Estado une a disidentes y adherentes al mismo tiempo que fragmenta principios, creencias, decisiones y acciones.

Si el Estado ha dividido a sus subsistemas en centrales y periféricos favoreciendo a los primeros y obstaculizando a los segundos, el Estado luhmaniano ha seducido a sus subsistemas hasta un punto tal en el que lo consideran imprescindible para su desarrollo. A pesar del liberalismo político, que supone la maximización de las libertades frente a la minimización de las igualdades, el Estado luhmaniano se erige como el gendarme por excelencia y legitimidad sin el cual, el mercado estaría condenado a su extinción. Es por ello que Rawls (1971) se aproxima a la concepción luhmaniana del Estado al considerar que una libertad sin Estado o por el contrario, el totalitarismo, son polos injustos cuyas consecuencias conver- 
gen en una distribución asimétrica del poder. Por ello, tanto Rawls como Luhmann están de acuerdo en que el Estado asuma el control limitado de la sociedad para perpetuarse como la institución política más importante de la historia.

\section{De este modo, el Estado es un sistema persuasivo que distribuye asimétricamente el poder para perpetuar su hegemonía sobre los subsistemas que lo configuran.}

Si el Estado busca su eternización y trascendencia complejizando su hegemonía política, entonces los subsistemas son factores externos e internos que fundamentan la autorganización del Estado.

Kymlicka observa un problema fundamental en la sociedad multicultural canadiense a la que expone como un conglomerado de diversidad. La preocupación del filósofo canadiense es muy parecida a la advertencia del filósofo ingles Rawls: la justicia en la equidad y la diversidad. En efecto, detrás de todo sistema político esta el dilema fundamental de la igualdad versus la libertad.

Un sistema en el que todos tienen el mismo punto de oportunidad y necesariamente tendrán un mismo punto de llegada o encuentro, es una sociedad altamente coercitiva y por ende, injusta. Un sistema en el que las oportunidades están reservadas para unos cuantos limita la libertad de elección y con ello amplifica la brecha entre los subsistemas favorecidos y los subsistemas excluidos. Por ello, tanto el filósofo canadiense como el filósofo norteamericano están a favor de la libertad en su más amplio sentido. Sin embargo, Kymlicka es menos efusivo al plantear que la participación ciudadana es la determinante de toda libertad y justicia en un sistema. En contraste Rawls (1971) considera que es el mismo sistema quien debe procurar la compatibilidad entre la libertad individual y la equidad social. Ambos, están a favor de la libertad que diversifique y al mismo tiempo unifique al sistema. Un Estado que promueve la libertad ciudadana para su participación acepta su restructuración en función de la diversidad de ideas. Un régimen que limita la libertad asume las consecuencias de la injusticia social. Una democracia injusta requiere de subsistemas para legitimarse y un Estado justo se legitima a partir de la libertad de sus elementos endógenos a costa de eliminar los factores externos.

La distribución de recursos en un sistema implica un problema fundamental en torno a su redistribución. En esencia, el Estado no podría encargarse de regular las relaciones entre sus elementos endógenos, pero puede otorgar libertades de decisión y acción. Por ello, en la concepción liberal de Nozick (1998), el Estado se enfoca en cuestiones mínimas tales como el derecho de propiedad y la seguridad de la misma. El Estado deja a la libre elección la competencia y la solidaridad entre sus elementos endógenos.

El Estado produce injusticia retributiva porque sólo atiende a las necesidades de quienes son propietarios de recursos.. En contraste, Rawls 
considera que el Estado debe impulsar la libertad de elección como contrapeso a las desigualdades endógenas del sistema. El Estado rawlsiano, a diferencia del nozickniano, maximiza la libertad y minimiza la desigualdad, se trata de un Estado en el que se produce justicia limitando las decisiones personales que contravienen el bienestar colectivo. Este mecanismo de coerción al individualismo requiere de mecanismos de consenso en donde los subsistemas endógenos participan racionalmente en el debate, votación, legislación e implementación de una ley reguladora de la competencia por los recursos. Nuevamente, la complejidad del sistema se asoma para insistir en el final de la coerción y el devenir de la persuasión.

\section{Violencia sociopolítica en México: prevalencia de homicidios}

El Instituto Ciudadano de Estudios Sobre la Inseguridad A. C. en su informe correspondiente al año 2010 relativo a los homicidios identifica al Estado de México como la entidad con mayor número de delitos de privación de la vida durante el periodo 1997 a 2010

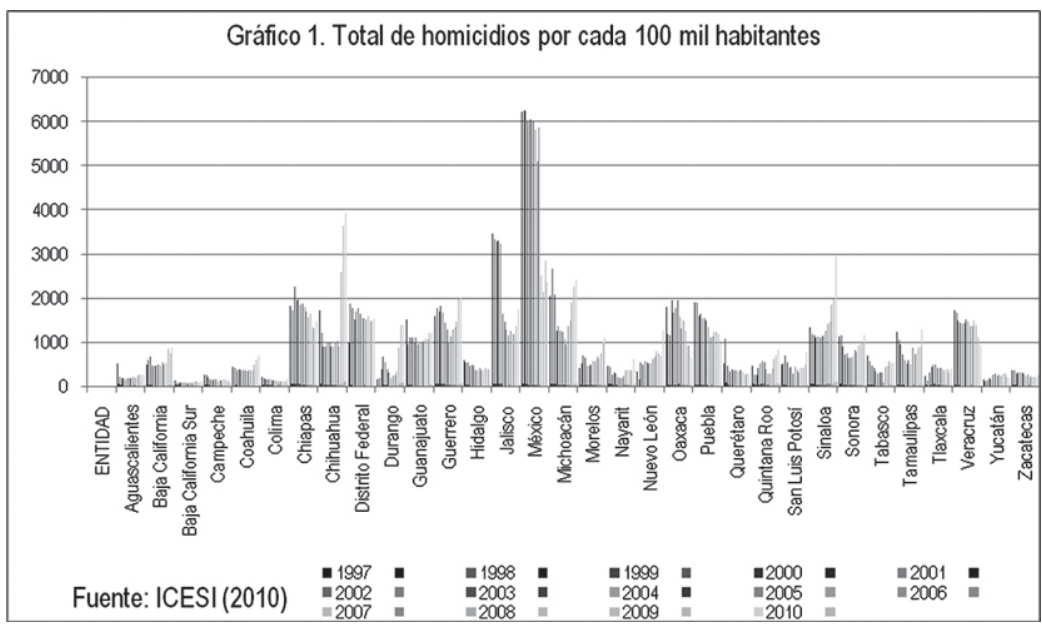

Alrededor de seis mil homicidios por cada 100 mil en promedio, El Estado de México lidera la lista de urbes más inseguras. En contraste, los estados de Baja California y Colima tuvieron el número más bajo de homicidios por cada 100 mil habitantes (ver gráfico 1).

Respecto a homicidios culposos definidos como lesiones no intencionadas de privar de la vida a una persona mediante cualquier objeto, 
el Estado de México y después Jalisco son las entidades con mayor riesgo de ser privado de la vida incidentalmente. Los estados de Baja California y baja California Sur tienen el menor número de los casos durante el mismo periodo de 1997 a 2010 (ver gráfico 2)

No obstante la tendencia de homicidios cometidos en el Estado de México y el estado de Jalisco, los homicidios dolosos se han presentado con mayor frecuencia en el estado de Chihuahua durante los últimos años. En este sentido, la prevalencia de casos de homicidios intencionales parece estar relacionado con la interacción entre los habitantes de estados Unidos de América (USA por sus siglas en ingles) y los Estados Unidos Mexicanos a lo largo de la frontera (ver gráfico 3).

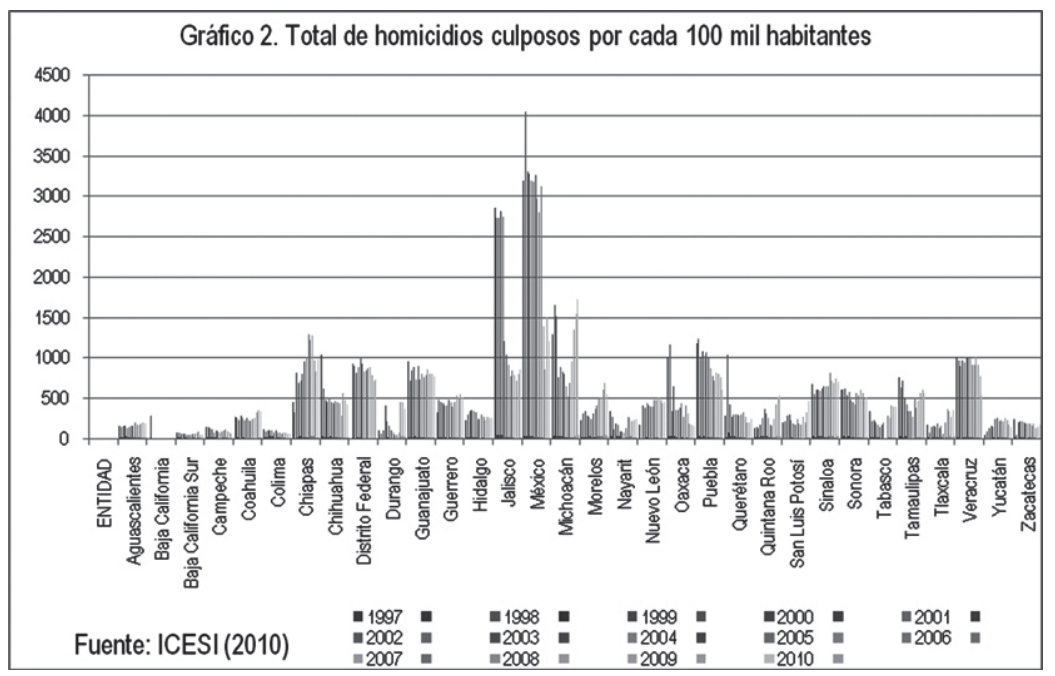

Por el contrario, los estados con el menor número de homicidios, Yucatán, Colima y baja California Sur parecen comprobar la hipótesis de la frontera insegura entre EUA y México. En el caso del estado de Sinaloa, los homicidios se han incrementado sustancialmente en los últimos años. No obstante, el Estado de México es la entidad en donde se comete más homicidios (ver gráfico 4, página 358). 
Polis, Revista Latinoamericana, Volumen 12, No 36, 2013

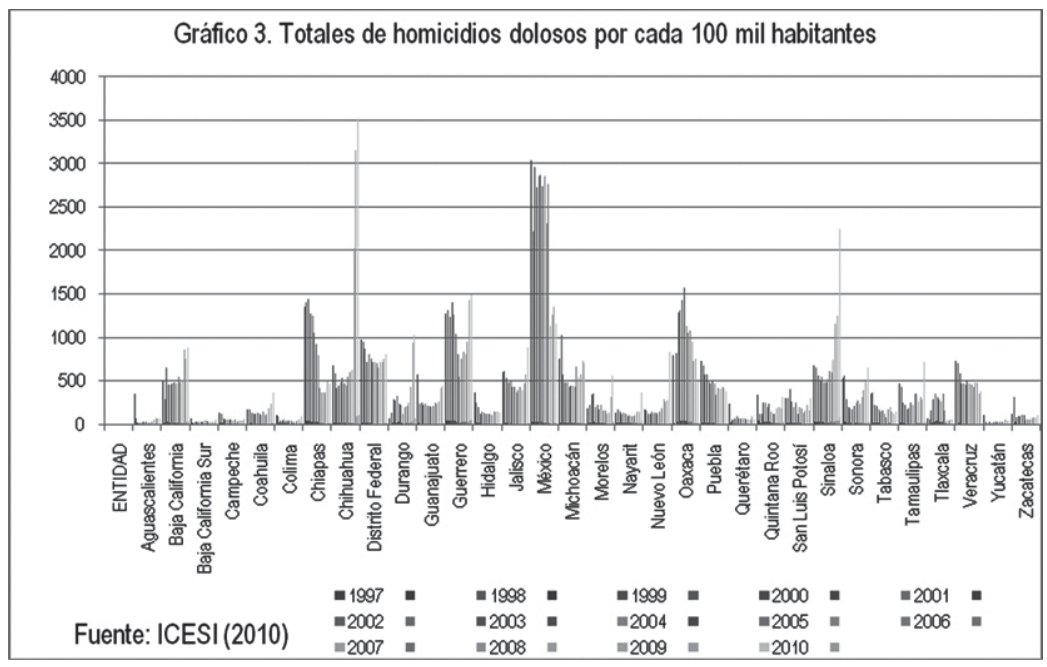

La tendencia de homicidios concentrada en el Estado de México es corroborada por la cantidad de homicidas del fuero común. Sin embargo, la Ciudad de México lidera este rubro con el mayor número de privadores de vida (ver gráfico 4)

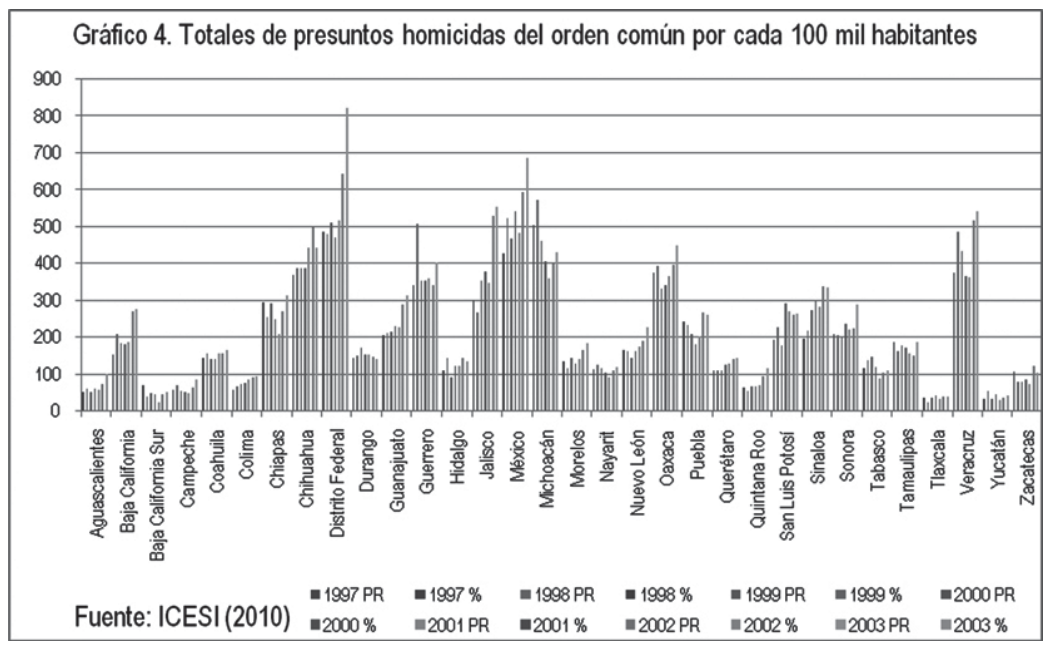

Respecto a la impunidad, el estado de Tlaxcala parece cometer el mayor número negligencias. 


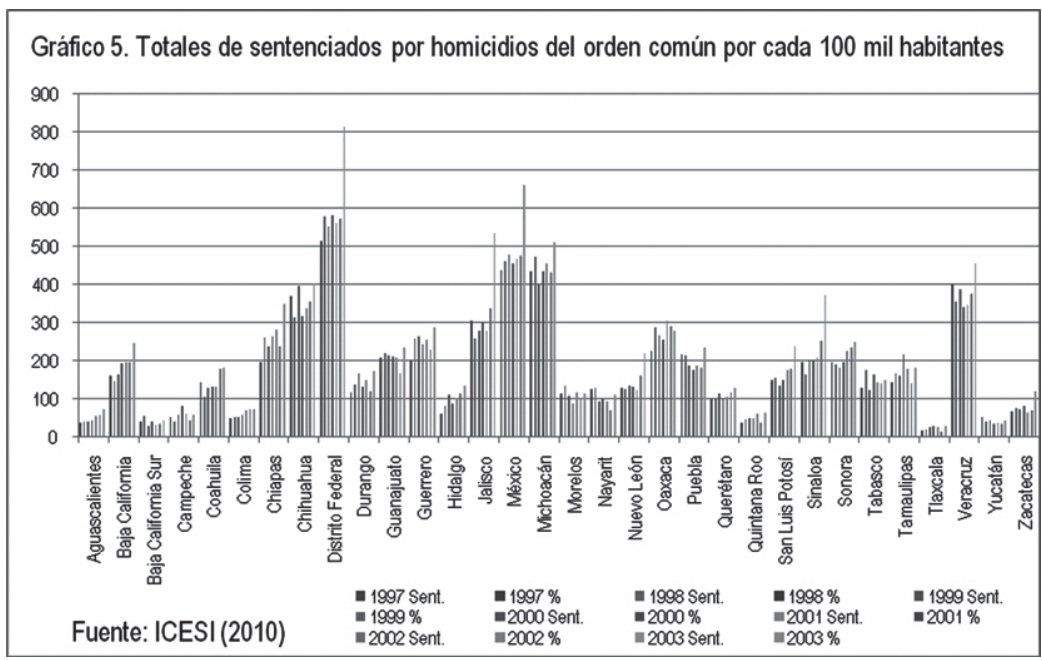

En el caso de la Ciudad de México, el mayor número de sentencias parece indicar un sistema eficaz de procuración e impartición de justicia puesto que de los 800 homicidas reportados todos fueron sentenciados.

En síntesis, la prevalencia de homicidios en el centro del país parece indicar un sistema de violencia sociopolítica en la que la opacidad, corrupción y negligencia serían los elementos consustanciales de la tendencia ascendiente de homicidios. En contraste, la violencia en la frontera norte, a pesar de tener una incidencia menor por cada 100 habitantes, ha sido magnificada por los medios de comunicación. El análisis y la discusión de ambos aspectos podrían llevarse a cabo considerando el enfoque de sistemas políticos y mediáticos así como el establecimiento de la agenda política a partir de los temas incluidos en la agenda de los medios y su incidencia en los temas de opinión pública.

\section{Teoría del Establecimiento de la Agenda}

En torno al concepto de agenda se han propuesto dos términos. El primero de Muñiz (2007: p. 92) define agenda como una colección de temas compartidos por comunicadores, políticos y audiencias. No obstante, los estudios sobre el establecimiento de la agenda se enfocan en el proceso por el cual los medios de comunicación seleccionan los temas que las audiencias recepcionaran como de suma importancia y posteriormente discutirán con base en los conceptos difundidos por los medios. Una segunda propuesta de Chihú (2011: p. 31) la define como un problema social, a menudo conflictivo, que ha recibido cobertura mediática sesgando la atención del público hacia determinados objetos o cuestiones de la escena polí- 
tica y social en los que el público confía y asigna importancia en función del grado de relevancia mediático.

La Teoría del Establecimiento de la Agenda (TEA) asegura que los medios de comunicación difunden temas de violencia a partir de sus intereses y no de la tendencia de casos del fuero común o federal. Igartua, Muñiz, Otero, Cheng y Gómez (2008: p. 5) plantean que los medios de comunicación masiva determinan y dictan los temas que la gente comentará. La opinión pública construirá percepciones sobre la importancia de los temas expuestos en los medios. Posteriormente, la gente comentará los temas incluso con las palabras utilizados por los profesionales de la comunicación en televisión, radio, prensa e internet. Obregón, Arroyave y Milena (2009: p. 24) plantean que el establecimiento de la agenda pública se construye con estrategias de contexto tales como; mayor primacía, cobertura, tiempo y espacio a noticias relativas. En esto consistiría el poder mediático ya que los medios de comunicación pueden enfatizar un tema sin tener que asumir riesgos.

La TEA explica la prevalencia de imágenes y sus efectos sobre la percepción de inseguridad de las audiencias y en el caso de los medios impresos, el efecto es en el discurso de sus lectores sobre la violencia y particularmente, los homicidios dolosos. De León (2008: p. 166) demostró que los medios de comunicación invisten de atributos los temas para facilitar su inclusión en la agenda pública. A través de los titulares y encabezados, los medios masivos de comunicación difunden expectativas en sus audiencias. Esto corrobora la hipótesis en torno a la cual los medios de comunicación influyen en la sociedad produciendo temas y colocándolos en la agenda de discusión pública. A partir de la TEA, sería posible explicar el proceso de construcción de la agenda mediática, pública y sobre todo política en torno a la inseguridad, la violencia, los homicidios, los perfiles y la impunidad que durante 1997-2010 ha azotado a México. En tal sentido, Penalva (1999: p. 159) sostiene que la Teoría del Establecimiento de la Agenda estaría más cercana al análisis de las noticias internacionales que la opinión pública no puede conocer directamente y por ello se ve sumamente influenciada por los medios de comunicación dado que otras fuentes de información, incluso internet, no ofrecen contenidos cercanos al entendimiento de las personas comunes y corrientes que aprenden con base en imágenes más que con base en discursos estructurados o razonamientos lógicos científicos.

Sin embargo, la TEA ha sido sumamente cuestionada en dos sentidos. En primera instancia, Cervantes (1999: p. 141) crítica el planteamiento de McCombs en torno al establecimiento de la agendasetting a las que considera como fases no inductivas en las que sólo se incluyen las noticias externas susceptibles de ser codificadas para demostrar la incidencia de los medios de comunicación en la opinión pública. En segundo lugar, Ugarte, Menéndez y Cuesta (2009: p. 79) critican el énfasis político en los temas que permitieron corroborar la hipótesis del establecimiento de la agenda. Reducen a las audiencias a meros espectadores incapaces de seleccionar 
información y construir su agenda de discusión. Paradójicamente, McCombs, a decir de los autores, concluye perfilando la investigación hacia los efectos psicológicos de los medios de comunicación en la opinión pública.

En torno al establecimiento de agenda-setting, los estudios mediáticos seleccionan, fragmentan y sesgan el ejercicio periodístico con estudios de sondeo simultáneo en el que las percepciones de los encuestados son una extensión de la agenda-setting de los medios. Por otra parte, los experimentos de recepción y percepción corroboran no sólo el sesgo informático, sino además su poder de influir en la opinión púbica.

No obstante, la TEA refiere solamente al sesgo informativo sin precisar un tiempo y espacio definidos para su comprobación empírica. En efecto, la tendencia ha sido medir simultáneamente, durante un lapso de tiempo determinado, el sesgo mediático y la influencia en la percepción de la gente.

Sin embargo, no es posible, realizar dos diagnósticos simultáneos de los hechos y concluir que existe una relación directa y significativa entre ellos. Si partimos de la premisa en torno a la cual un hecho es observable simultáneamente más de una vez entonces tendríamos que pensar que la percepción si y sólo si esta influida por los medios olvidando que puede estar influida por el hecho en sí, por otros acontecimientos relacionados, por experiencias directas, indirectas e incluso por otras notas informativas. McCombs (1972) sostiene que el sesgo informativo es inherente al ejercicio periodístico y esto significa que en realidad los medios no influyen directamente en la agenda-setting pública. Es decir, los medios son sólo intermediarios de los errores del ejercicio periodístico.

En todo caso, la hipótesis en torno la cual los medios sesgan la información e influyen en la opinión pública puede ser contrastada si consideramos el sesgo sistemático de la información. Esto es, si los medios repetidamente maximizan o minimizan un hecho entonces podríamos esperar que traten de influir en la gente. Vázquez (2004: p. 268) plantea que al construir una agenda mediática, los medios de comunicación construyen una agenda pública y política esencial para el Estado. Es decir, los medios de comunicación utilizan marcos de referencia en los que la opinión pública se basa para construir su agenda de discusión pública. Se trata de atributos en torno a un tema que orientan la percepción, selección y recepción de la información por parte de las audiencias. García (2007: p. 31) sostiene que el establecimiento de la agenda es un efecto de resonancia informativa en el que los medios emiten temas que a posteriori las audiencias amplificaran o disminuirán su relevancia, pero en definitiva incluirán en su agenda de discusión una vez que los medios se han encargado de difundir la noticia. Luengo (2009: p. 114) relaciona el establecimiento de la agenda con la formación de actitudes y decisiones de discusión en torno a los temas seleccionados por los medios y aceptados por la opinión pública como los asuntos públicos de mayor interés e importancia. Se trata de un efecto mediático que construye la opinión pública a través de sus expectativas e 
intenciones de llevar a cabo una discusión pública al interior del grupo de referencia o pertenencia.

\section{Discusión}

En México los casos de homicidios ocupan un lugar preponderante en la agenda mediática, pública y política. En tanto tendencia de violencia social, los homicidios, principalmente los dolosos, al ser difundidos por los medios de comunicación, repercuten en la opinión pública, principalmente en su percepción de inseguridad.

De acuerdo con el Instituto Ciudadano de Estudios sobre la Inseguridad (ICESI), la tendencia de homicidios se ha concentrado en el Estado de México. En dicha entidad, los homicidios dolosos y el número de homicidas se han incrementado durante el periodo que va de 1997 a 2010 . No obstante, el número de sentencias ha disminuido notablemente.

A pesar de que esta tendencia es estadísticamente consistente con los reportes del Instituto Nacional de Estadística, Geografía e Informática (INEGI) correspondientes al informe de 2010, los medios de comunicación parecen concentrar sus esfuerzos en demostrar la hipótesis en torno la cual se considera a las ciudades fronterizas con los Estados Unidos de América (EUA) como las más inseguras del país. O bien, los medios de comunicación parecen enfocar su cobertura en los estados identificados como entidades de narcotráfico en el que los cárteles se disputan el territorio e incrementan con ello, la inseguridad, la violencia y los homicidios.

Sin embargo, la tendencia de los homicidios reportados por el ICESI, INEGI y los medios de comunicación parecen no coincidir con las percepciones de inseguridad reportadas por los estudios del estado del arte. En estas investigaciones, los homicidios son considerados como el resultado de estados emocionales o características sociodemográficas que hacen más proclive la comisión del delito. Es decir, los perfiles socioeconómicos, demográficos y psicológicos de los homicidas parecen indicar que la privación ilícita de la vida es el resultado de una combinación de tendencias estadísticas que determinarían la comisión del delito.

En síntesis, la tendencia de los datos reportados por el ICESI e INEGI parece contradecir la cobertura de los medios de comunicación y las percepciones de inseguridad esgrimidas en el estado del arte. Para demostrar esta aseveración es indispensable estructurar metodológicamente un estudio longitudinal.

La primera etapa necesariamente sería retrospectiva porque el registro de los hechos puede compararse con la cobertura mediática y en consecuencia, establecer sus diferencias con base en el sesgo sistemático informativo. 
Demostrado el sesgo sistemático, la segunda etapa consistiría en la demostración del efecto del sesgo informativo en la percepción de la gente. En este sentido, resulta fundamental delimitar o circunscribirnos a los hechos relevantes que pueden estar presentes en la memoria de la opinión pública. Tales son los casos del «Casino Royal», «las ejecuciones de migrantes», «La Caravana por la paz con justicia y dignidad» entre otros que al estar presentes en la memoria colectiva pueden ser evidencia de la relación causal entre la cobertura mediática y la percepción.

En esta segunda fase, habría que demostrar la presencia de los hechos relevantes en la memoria colectiva. Para tal fin, se le preguntaría a las personas que nombrasen los diez hechos más importantes según sus experiencias y los diez eventos según la prensa. Una vez recabada la información, se construirían reactivos con contenidos de los eventos relevantes y se aplicarían a una muestra de las personas previamente entrevistadas. Posteriormente, se construirían reactivos con las citas textuales de la cobertura mediática y se aplicarían a la misma muestra. Los resultados esperados podrían indicar una relación entre los reactivos de las experiencias y los reactivos de la cobertura mediática.

La contrastación de los dos principios de la Teoría del Establecimiento de la Agenda no sólo explicaría el sesgo y la manipulación informativa de los medios de comunicación sobre la opinión pública, además develaría la opinión pública de las políticas, programas y acciones de gobierno ante la inseguridad y la violencia. En la medida en que los medios de comunicación intensifiquen los contenidos de su agenda, propiciarán un aumento en la opinión ciudadana respecto a la procuración e impartición de justicia, y un decremento de la opinión crítica. En este sentido, el establecimiento de la agenda de seguridad nacional ya no sólo se realizaría desde los medios para incidir en las estrategias de las fuerzas coercitivas tales como la gendarmería, la armada, el ejército o la policía, sino desde la persuasión y la evaluación ciudadana de las políticas públicas y sociales relativas a combatir los noticieros, los editoriales o los documentales alejados de las mediciones académicas de inseguridad y violencia. 
Polis, Revista Latinoamericana, Volumen 12, $N^{\circ}$ 36, 2013

\section{Bibliografía}

Bauman, Zygmunt (1998), La globalización: consecuencias humanas. FCE, México.

Ídem (2002), La sociedad sitiada. FCE, México.

Ídem (2005), Vida Líquida. Paidós, Barcelona.

Ídem (2008), Vida de consumo. Anthropos, Barcelona.

Bertalanffy, Ludwig (1968), General System Theory: Foundations, Development, Applications. George Braziller, New York.

Cervantes, Cecilia (1999), “La sociología de las noticias como vía para renovar la investigación en la línea agendasetting: revisión de interpretaciones”. Comunicación y Sociedad, 36, 133-152.

Chihú, Aquiles (2011), El Framing del spot político. UAM-Porrúa, México

De León, Salvador (2008), “Notas para una exploración teórica sobre los estudios de producción de comunicación mediática (periodismo, opinión pública y comunicación política)”. Comunicación y Sociedad, 9, 145-173.

García, Javier (2007), El comportamiento de la prensa durante los conflictos de Kosovo e Irak. Tesis de Doctorado. Universidad de Granada.

Giddens, Anthony (1979), Central problems in social theory: Action, structure and contradiction in social analysis. UCLA, Berkley.

Ídem (1991), Structuration theory: past, present and future. Giddens Theory of structuration. A critical appreciation. Ed. Jary, David, Routledge, London.

Instituto Ciudadano de Estudios Sobre la Inseguridad (2010), Informe anual de la inseguridad. ICESI, México.

Instituto Nacional de Estadística, Geografía e Informática (2010), XII Censo Nacional de Población y Vivienda. INEGI, México.

Kymlicka, Will (1969), Liberalism, Community, and Culture. Oxford University Press, Oxford.

Ídem (1995), Filosofía política contemporánea. Ariel, Barcelona.

Luengo, María (2009), “Desde los efectos mediáticos hasta la influencia cultural: fundamentos analíticos para la interpretación simbólica de los medios”. Análisis, 39, 113-129. 
Luhmann, Niklas (1986), Complejidad y Democracia. Sistemas políticos: términos conceptuales. UAM-A, México.

Ídem (1992), Sociología del riesgo. UdeG, México.

McCombs, M. (1972), “The agendasetting function of mass media”. The public Opinion Quarterly 36, 176-187.

Muñiz, Carlos (2007), Encuadres noticiosos e inmigración: del análisis de los contenidos al estudio de los efectos mediáticos. Tesis de Doctorado. Universidad de Salamanca.

Nozick, Robert (1998), Anarquía, Estado y Utopía, FCE, México.

Penalva, Clemente (1999), "La selección de noticias como indicador de desigualdad entre naciones”. Papers 59, 155-172.

Rawls, John (1971), A theory of justice. Harvard University Press, Cambridge.

Ugarte, Aitor, Menéndez, Tania y Cuesta, Ubaldo (2009), Prensa escrita y salud en Madrid. Universidad Complutense de Madrid, España.

Vázquez, Annel (2004), “Más allá de Habermans: la realidad de los medios de comunicación”. Comunicación y Sociedad 2, 247-273.

Recibido: 20.07.2012

Aceptado: 10.04.2013 